\title{
The current clinical relevancy of intraoral scanners in implant dentistry
}

\author{
Takashi SAWASE* and Shinichiro KUROSHIMA* \\ Department of Applied Prosthodontics, Institute of Biomedical Sciences, Nagasaki University, 1-7-1 Sakamoto, Nagasaki 852-8588, Japan \\ Corresponding author, Takashi SAWASE; E-mail: sawase@nagasaki-u.ac.jp
}

\begin{abstract}
Optical technology has provided a paradigm shift in implant dentistry. However, there is little information about the use of optical technology in implant dentistry, since this technology is relatively new and has been evolving under the current conditions. In the present narrative literature review, the effects of intraoral scanners (IOSs) use on accuracy and the operating time, as well as safety and patient perception, in implant dentistry were evaluated from the clinical perspective. The accuracy of digital scans with IOSs was comparable to the conventional impression techniques for single or partial prostheses, and the digital scans with IOSs are time efficient when taking impressions for single- or double-abutments. However, the accuracy and time efficiency are decreased for multiple implant scans or large-area scans with IOSs use. Patient satisfaction with and preference for IOSs scans are generally superior to those with conventional impression procedures.
\end{abstract}

Keywords: Digital dentistry, Intraoral scanner, Clinical relevancy

\section{INTRODUCTION}

The term "digital dentistry" first appeared in PubMed back in $1999^{1}$. In these last two decades, digital dentistry has spread widely in the prosthodontic fields. It has been applied to fixed partial dentures ${ }^{2-4)}$, complete dentures ${ }^{5)}$, and maxillofacial prostheses ${ }^{6}$. It has also contributed greatly, from treatment planning to the definitive prosthetic work, in implant dentistry ${ }^{7}$. Digital dentistry is a field with high future growth potential, though there are some issues that need to be addressed because the field is still evolving.

The essential step on the digital path is digitization of the dentition by digital scanning. Digitization of the dentition was first introduced using an indirect scan of the stone model, and then, recently, direct intraoral scanning, so-called digital impression, has come into the clinic in conjunction with CAD/CAM technology. Intraoral scanners (IOSs) could change the daily routine practice of both dentists and dental technicians. It has been suggested that IOSs may obviate the need for impression trays, impression materials, and stone casts, and shipping to a laboratory will no longer be required ${ }^{8-111}$. The electronic files can be digitally sent and stored saving, time, cost, and space. These fascinating advantages are considered to be quite useful in implant dentistry. Digital implant impressions with IOSs not only do not need impression trays and materials, but also impression copings, so that patients can avoid opening their mouths widely during the impression. Digital impressions can be achieved by optical acquisition for simply connected scan bodies instead of the screw tightening and loosening of impression copings ${ }^{12)}$. Obviously, a higher impression accuracy is needed for implant-supported prostheses. Even so, no impression technique could achieve an absolute passive fit ${ }^{13-15}$. As for the conventional implant impressions with open or closed tray technique, despite the fact that deformation of the impression materials and expansion of the stone cast may result in the misfit of the prostheses, successful outcomes have been achieved in clinical practice ${ }^{16-20)}$. The biologic tolerance of the bone around the implant could compensate for the misfit ${ }^{21}$. Therefore, a certain amount of misfit is accepted in daily clinical practice.

The aim of the current narrative literature review is to access whether IOSs can be used in implant prosthetic work. The accuracy and operating time with IOSs, as well as safety and patient perception, were evaluated from the clinical perspective.

\section{ACCURACY OF IOSS IN IMPLANT DENTISTRY}

Accuracy is defined as the "closeness of agreement between a measured quantity value and a true quantity value of a measurand", and it is expressed by trueness and precision ${ }^{22,23)}$. Trueness represents the closeness of the measurement to the accepted reference value, whereas precision represents the closeness of repeated measurement of the same object. The precision of IOSs can be measured easily in vivo by repetitive captures of the object and assessment of their reproducibility, whereas the calculation of trueness is slightly difficult. A sophisticated scanner, such as an industrial coordinate measuring machine, is needed to obtain a reliable reference model. The trueness of IOSs is calculated by the closeness of agreement between the measurement result and a true value.

Several studies have compared accuracy with specific mention of trueness and precision of different IOSs in implant dentistry ${ }^{24-28}$, as summarized in Table 1. The partial prosthesis and the full arch prosthesis in Table 1 were assumed to be a 3-unit implants-supported bridge and a 6-unit implant-supported bridge from molar to molar region, respectively. Table 1 shows the significant

*Authors who contributed equally to this work. 
Table 1 Truness and precision of IOS in implant dentistry

\begin{tabular}{|c|c|c|c|c|c|c|c|c|}
\hline \multirow{2}{*}{$\begin{array}{l}\text { Author } \\
\text { (Year) }\end{array}$} & \multirow{2}{*}{ IOS } & \multicolumn{2}{|c|}{ Single prosthesis } & \multicolumn{2}{|c|}{ Partial prosthesis } & \multicolumn{2}{|c|}{ Full arch prosthesis } & \multirow{2}{*}{$\begin{array}{c}\text { reference } \\
\text { No. }\end{array}$} \\
\hline & & $\begin{array}{l}\text { Trueness } \\
(\mu \mathrm{m})\end{array}$ & $\begin{array}{l}\text { Precision } \\
(\mu \mathrm{m})\end{array}$ & $\begin{array}{l}\text { Trueness } \\
(\mu \mathrm{m})\end{array}$ & $\begin{array}{l}\text { Precision } \\
(\mu \mathrm{m})\end{array}$ & $\begin{array}{l}\text { Trueness } \\
(\mu \mathrm{m})\end{array}$ & $\begin{array}{l}\text { Precision } \\
(\mu \mathrm{m})\end{array}$ & \\
\hline \multirow{2}{*}{$\begin{array}{l}\text { Ajioka } \\
\text { et al. } \\
(2016)\end{array}$} & Lava COS & - & - & $64.5 \pm 19.0$ & $15.6 \pm 10.9$ & - & - & \multirow[b]{2}{*}{ 26) } \\
\hline & $\begin{array}{l}\text { Conventional } \\
\text { impressions }\end{array}$ & - & - & $22.5 \pm 12.4^{*}$ & $13.5 \pm 8.6$ & - & - & \\
\hline \multirow{4}{*}{$\begin{array}{l}\text { Chew } \\
\text { et al. } \\
(2017)\end{array}$} & Trios 3 & - & - & $64.0 \pm 20.0$ & - & - & - & \multirow{4}{*}{ 27) } \\
\hline & iTero & - & - & $62.0 \pm 18.0$ & - & - & - & \\
\hline & True Definition & - & - & $63.0 \pm 17.0$ & - & - & - & \\
\hline & $\begin{array}{l}\text { Conventional } \\
\text { impressions }\end{array}$ & - & - & $35.0 \pm 6.0$ & - & - & - & \\
\hline \multirow{4}{*}{$\begin{array}{l}\text { Imburgia } \\
\text { et al. } \\
(2017)\end{array}$} & CS 3600 & - & - & $45.8 \pm 1.6$ & $24.8 \pm 4.6$ & $60.6 \pm 11.7$ & $65.5 \pm 16.7$ & \multirow{4}{*}{ 24) } \\
\hline & Trios 3 & - & - & $50.2 \pm 2.5$ & $24.5 \pm 3.7$ & $67.2 \pm 6.9$ & $31.5 \pm 9.8$ & \\
\hline & Omunicam & - & - & $58.8 \pm 1.6$ & $26.3 \pm 1.5$ & $66.4 \pm 3.9$ & $57.2 \pm 9.1$ & \\
\hline & True Definition & - & - & $61.4 \pm 3.0$ & $19.5 \pm 3.1$ & $106.4 \pm 23.1$ & $75.3 \pm 43.8$ & \\
\hline \multirow{4}{*}{$\begin{array}{l}\text { Mangano } \\
\text { et al. } \\
(2016)\end{array}$} & Trios 2 & - & - & $71.2 \pm 19.5$ & $51.0 \pm 18.5$ & $71.6 \pm 26.7$ & $67.0 \pm 32.2$ & \multirow{4}{*}{ 25) } \\
\hline & CS 3500 & - & - & $47.8 \pm 7.3$ & $40.8 \pm 6.4$ & $63.2 \pm 7.5$ & $55.2 \pm 10.4$ & \\
\hline & Zfx Intrascan & - & - & $117.0 \pm 28.6$ & $126.2 \pm 21.2$ & $103.0 \pm 26.9$ & $112.4 \pm 22.6$ & \\
\hline & $\begin{array}{l}\text { Planmeca } \\
\text { Planscan }\end{array}$ & - & - & $233.4 \pm 62.6$ & $219.8 \pm 59.1$ & $253.4 \pm 13.6$ & $204.2 \pm 22.7$ & \\
\hline \multirow{5}{*}{$\begin{array}{l}\text { Mangano } \\
\text { et al. } \\
(2019)\end{array}$} & Trios 3 & $22.3 \pm 0.5^{*}$ & $15.2 \pm 0.8$ & $28.5 \pm 0.5^{*}$ & $21.0 \pm 1.9$ & $46.3 \pm 4.9$ & $36.5 \pm 3.4$ & \multirow{5}{*}{ 28) } \\
\hline & CS 3600 & $15.2 \pm 0.8^{*}$ & $11.3 \pm 1.1$ & $23.0 \pm 1.1^{*}$ & $17.0 \pm 2.3$ & $44.9 \pm 8.9$ & $35.7 \pm 4.3$ & \\
\hline & Omunicam & $28.4 \pm 4.5^{*}$ & $30.6 \pm 3.3$ & $38.1 \pm 8.8^{*}$ & $43.2 \pm 9.4$ & $70.4 \pm 11.9$ & $89.3 \pm 14.0$ & \\
\hline & DWIO & $27.8 \pm 3.2^{*}$ & $27.1 \pm 10.7$ & $49.8 \pm 5.0$ & $34.8 \pm 10.8$ & $92.1 \pm 24.1$ & $111.0 \pm 24.8$ & \\
\hline & Emerald & $43.1 \pm 11.5$ & $32.8 \pm 10.7$ & $49.3 \pm 5.5$ & $29.9 \pm 8.9$ & $66.3 \pm 5.6$ & $61.5 \pm 18.1$ & \\
\hline
\end{tabular}

* The values of trueness $<30 \mu \mathrm{m}$ of threshold

differences between the various IOSs examined, both in trueness and precision. There was a clear tendency showing that more errors could be found as the scan area became larger. In the latest research by Mangano et $a l$., the critical threshold of trueness was set at $30 \mu \mathrm{m}^{28)}$. Other previous clinical studies have shown that the biological and technical complications increased when misfit of 30 to $150 \mu \mathrm{m}$ was found between the prosthetic framework and the implant abutments ${ }^{29,30)}$. Applying the 30- $\mu \mathrm{m}$ threshold for trueness to Table 1, four and two of the five modern IOSs showed excellent trueness within the allowable threshold for single and partial prostheses, respectively. Notably, though the same IOSs (Trios 3 and CS 3600) were used in different articles ${ }^{24,28)}$, the results for trueness for the partial prosthesis and the full arch prosthesis were quite different. Of course, the reference models were different, and the acquisition software has been substantially improved, since the latest article ${ }^{28)}$ showed improved accuracy. The accuracy is dependent not only on the optical scanning devices, but also the software used. Basically, the acquired surface data by IOSs would be arranged in a common coordinate system, and then image reconstruction would be carried out. The surface of an object is recognized as point clouds, and then highly specific software algorithms reconstruct the virtual surface image by stitching together, filtering, and converting the various point clouds $^{31-33)}$. Due to the humid environment and the different materials and textures, such as an enamel and various restorative materials in the oral cavity, as well as the patient's movements, direct intra oral scanning can be especially challenging. Furthermore, when imaging with teeth, a higher resolution of acquisition is needed to make visible the margin of the prosthetic preparation and morphological variables among different individuals ${ }^{34}$. On the other hand, in implant dentistry, intraoral scan bodies (ISBs), 
which are directly connected to the implants, were used as the scan object instead. It may be beneficial for digital implant impressions, because ISBs dimensions and unique features were input ahead of time into the software. In addition, dull, smooth, and opaque surfaces of ISBs could contribute to easier scanning. Since digital implant impressions aim to capture not refined finish lines of the preparation but their position, IOSs are suitable for implant impressions ${ }^{35-37}$. Consequently, ISBs play an important role in digital implant impressions. Recently, Mizumoto and Yilmaz reviewed ISBs in implant dentistry to identify key ISB features in relation to intraoral scanning technology ${ }^{38}$. They summarized almost all commercially available ISBs and then reported that the commercial ISB design is highly variable with regard to material, shape, size, surface, connection, reusability, software/scanner compatibility, and cost. Nevertheless, they failed to identify desirable specific ISB features, and the accuracy of digital scans with ISBs was comparable to the conventional impression techniques ${ }^{21,39,40)}$.

On the other hand, there are some caveats to be taken into account. Four of eight ISBs in that review fully consisted of polyether ether ketone (PEEK), whereas the majority of the implant abutments consist of titanium or titanium alloy. Since there is a big difference, in double-figures, of the elastic modulus between PEEK and titanium or titanium alloy ${ }^{41,42}$, fitting and/ or matching against the implant might be affected. It has been reported that the abutment settled down after screw tightening according to the applied torque and the material in the current major implant joint system of the internal conical connection ${ }^{43}$. Another caveat of the ISBs was the wear through repeated use and sterilization. These caveats may cause changes in positioning of ISBs, resulting in inaccurate transfer of the implant position. Nevertheless, used of an ISB is a decisive factor for a high-precision transfer of the implant position and inclination, there is limited information available on the physical features of the ISBs, and more studies are needed to investigate the relationships between ISB features and digital scanning accuracy.

\section{TIME EFFICIENCY OF IOSs}

Some reviews including literature and systematic reviews, as well as in vitro and clinical studies, have demonstrated that IOS use can, under certain conditions, significantly reduce impression time when compared with conventional approaches using impression materials and trays, although many studies included other clinical steps such as antagonist scans, occlusal bite record scans and data processing of IOSs when investigating time efficiency ${ }^{8,40,44-48)}$. An in vitro experimental study using 3 types of IOSs reported that the mean total time of IOS scans for single- and doubleabutments was $5.25 \pm 0.72$ (mean \pm standard deviation) and $5.88 \pm 0.73$ (mean \pm standard deviation) min, respectively. Conversely, 21.9 \pm 3.1 (mean \pm standard deviation) $\mathrm{min}$ are required to complete conventional impressions for single- and double-abutments, which indicates that IOS impressions are approximately 4 times faster than conventional procedures using impression materials in vitro ${ }^{46}$. On the other hand, the same study demonstrated that mean total time to complete full arch impression (14 abutments) is $19.51 \pm 1.56$ (mean \pm standard deviation) and 24.9 \pm 3.07 (mean \pm standard deviation) $\mathrm{min}$ for IOS and conventional procedures, respectively, although the measurement time included the abutment scans, antagonist scans, bite registration scan, and data processing time in this in vitro study ${ }^{46}$. Therefore, these finding suggests us that IOS use is time efficient when taking impressions for single- or double-abutments, whereas the efficiency is not clearly noted for multiple teeth scans when an IOS is used for impressions in vitro.

Data similar to an in vitro study has been obtained clinically. A comparative clinical study demonstrated that the treatment time including natural single tooth impressions, antagonist impression, and bite records was $4.14 \pm 0.38$ (mean \pm standard deviation) and $10.1 \pm 0.39$ (mean \pm standard deviation) $\mathrm{min}$ for IOS use and conventional silicone impression, respectively ${ }^{47}$. A withinsubject comparison study comparing treatment time for single implant impression by IOS with conventional impression showed that mean treatment time including some processes was $5.65 \pm 1.85$ (mean \pm standard deviation) and $12.2 \pm 1.4$ (mean \pm standard deviation) $\mathrm{min}$ for IOS and the conventional approach, respectively ${ }^{40)}$. A randomized controlled trial has demonstrated that single-implant impression with a scan body using an IOS significantly reduced mean total work time, including preparation of the IOS software, insertion of the scan body, effective scan time, and removal of the scan body, when compared with conventional impression including insertion of the transfer coping, preparation of the pre-fabricated impression tray, and impression procedure with elastomeric material including setting and removal of the tray [4.53 \pm 1.34 (mean \pm standard deviation) vs. $10.09 \pm 1.5$ (mean \pm standard deviation) $\mathrm{min}$ for IOS and conventional impressions, respectively] ${ }^{45)}$. Thus, it was concluded that single tooth- and/or singleimplant impressions using an IOS contribute to time efficiency under clinical situations. On the other hand, the evidence for the use of IOS for full-arch impression is insufficient ${ }^{48}$. Based on scientific data regarding time efficiency, use of an IOS for multiple-teeth and/or implant impressions may not be necessary in the current clinical situations.

On the other hand, it has been reported that IOS use contributes to the reduction of clinical working time when fitting and adjusting an implant-supported single crown in the clinical situation $[2.1 \pm 2.1$ (mean \pm standard deviation) vs. 6.0 \pm 3.9 (mean \pm standard deviation) $\mathrm{min}$ for digital and conventional procedures, respectively], although this study compared digital workflow using both IOS and CAD/CAM technology with conventional workflow using impression materials, stone casts and lost-wax technique ${ }^{49}$. Thus, IOS use may also decrease working time in the dental laboratory, since it obviates 
the need for stone casts and their transportation from the clinic to the dental laboratory.

\section{SAFETY AND PATIENT PERCEPTION}

Impression techniques when fabricating dental prostheses often induce patient discomfort. Conventional impressions using impression materials and trays are particularly uncomfortable for patients due to the gagging reflex $^{50)}$. Moreover, conventional impressions may not be appropriate for elderly patients due to the occurrence of serious clinical issues such as missswallowing and/or aspiration.

A recent clinical study using a $100-\mathrm{mm}$ visual analogue scale (VAS) for IOS use demonstrated that one IOS significantly improved patient comfort and preference compared with other IOSs and conventional impression using alginates ${ }^{51)}$. A within-subject comparison study including a VAS questionnaire reported that use of IOS significantly decreased patient discomfort, shortness of breath, and feelings of helplessness when compared with conventional impression methods with alginates. As a result, 41 of 50 patients preferred IOS over alginate impressions ${ }^{40)}$. Moreover, a clinical trial comparing conventional impressions using polyether materials with IOS use for a single tooth demonstrated that IOS use significantly decreased discomfort in mouth opening and in the TMJ, queasiness, and breathing difficulty. The same study has also reported that IOS use rarely affected smell/voice and tooth and periodontal sensitivity as compared with conventional impressions ${ }^{47}$.

Generally, impression materials, impression copings, and trays are used with conventional impressions for dental implants to transfer the intra-oral position of dental implants into a working stone cast for fabricating implant-supported prostheses. In particular, screwretained impression copings and open impression trays are preferentially used to establish a higher accuracy of impressions. However, more mouth opening is required with the use of screw-retained impression copings, since the screw retention must be loosened using screw drivers through the holes on top of the impression trays when the impressions are removed from the patient's mouth. On the other hand, optical impressions using an IOS for dental implants do not require excessive mouth opening, since scan bodies inserted in dental implants are simply scanned by an IOS to record the positions of dental implants ${ }^{12)}$.

Therefore, these above-mentioned findings suggest that patient satisfaction and preference with IOSs are generally superior to those with conventional impression procedures $^{8,40,47,51)}$. However, these patient-related factors may differ in an IOS-dependent manner ${ }^{51)}$.

\section{CONCLUSIONS}

Based on the findings of this review, the following conclusions were drawn:

1. The accuracy of digital scans with IOSs was dependent on the optical scanning devices and software used and was comparable to the conventional impression techniques for single or partial prostheses.

2. ISBs are the typical composing element and play an important role in digital implant impressions, but they are not well understood.

3. The digital scans with IOSs provide time efficiency when taking impressions for single- or doubleabutments. ISBs are complex implant position transfer devices with considerable variability in features and design.

4. Patient satisfaction and preference with the use of IOSs are generally superior to those with conventional impression procedures.

5. The use of IOSs appears promising, although more studies are needed to investigate the efficacy of digital intraoral implant impressions.

\section{REFERENCES}

1) Schleyer TK. Digital dentistry in the computer age. J Am Dent Assoc 1999; 130: 1713-1720.

2) Sannino G, Germano F, Arcuri L, Bigelli E, Arcuri C, Barlattani A. CEREC CAD/CAM chairside system. Oral Implantol 2015; 7: 57-70.

3) Brawek PK, Wolfart S, Endres L, Kirsten A, Reich S. The clinical accuracy of single crowns exclusively fabricated by digital workflow -the comparison of two systems. Clin Oral Investig 2013; 17: 2119-2125.

4) de Paula Silveira AC, Chaves SB, Hilgert LA, Ribeiro AP. Marginal and internal fit of CAD-CAM-fabricated composite resin and ceramic crowns scanned by 2 intraoral cameras. $J$ Prosthet Dent 2017; 117: 386-392.

5) Infante L, Yilmaz B, McGlumphy E, Finger I. Fabricating complete dentures with CAD/CAM technology. J Prosthet Dent 2014; 111: 351-355.

6) Jiao T, Zhu C, Dong X, Gu X. Rehabilitation of maxillectomy defects with obturator prostheses fabricated using computeraided design and rapid prototyping: a pilot study. Int $\mathrm{J}$ Prosthodont 2014; 27: 480-486.

7) Hämmerle $\mathrm{CH}$, Cordaro L, van Assche N, Benic GI, Bornstein M, Gamper F, et al. Digital technologies to support planning, treatment, and fabrication processes and outcome assessments in implant dentistry. Summary and consensus statements. The 4th EAO consensus conference 2015. Clin Oral Implants Res 2015; 26: 97-101.

8) Mangano F, Gandolfi A, Luongo G, Logozzo S. Intraoral scanners in dentistry: a review of the current literature. BMC Oral Health 2017; 17: 149.

9) Joda T, Zarone F, Ferrari M. The complete digital workflow in fixed prosthodontics: a systematic review. BMC Oral Health 2017; 17: 124.

10) Lee H, Cha J, Chun YS, Kim M. Comparison of the occlusal contact area of virtual models and actual models: a comparative in vitro study on Class I and Class II malocclusion models. BMC Oral Health 2018; 18: 109.

11) Mühlemann S, Kraus RD, Hämmerle CHF, Thoma DS. Is the use of digital technologies for the fabrication of implantsupported reconstructions more efficient and/or more effective than conventional techniques: A systematic review. Clin Oral Implants Res 2018; 29(Suppl 18): 184-195.

12) Flügge TV, Att W, Metzger MC, Nelson K. Precision of dental implant digitization using intraoral scanners. Int J Prosthodont 2016; 29: 277-283.

13) Kan JY, Rungcharassaeng K, Bohsali K, Goodacre CJ, Lang BR. Clinical methods for evaluating implant framework fit. J 
Prosthet Dent 1999; 81: 7-13.

14) Sahin S, Cehreli MC. The significance of passive framework fit in implant prosthodontics: current status. Implant Dent 2001; 10: 85-92.

15) de Sousa SA, de Arruda Nobilo MA, Henriques GE, Mesquita MF. Passive fit of frameworks in titanium and palladiumsilver alloy submitted the laser welding. J Oral Rehabil 2008; 35: 123-127.

16) Johnson GH, Craig RG. Accuracy of four types of rubber impression materials compared with time of pour and a repeat pour of models. J Prosthet Dent 1985; 53: 484-490.

17) Millstein PL. Determining the accuracy of gypsum casts made from type IV dental stone. J Oral Rehabil 1992; 19: 239-243.

18) Faria AC, Rodrigues RC, Macedo AP, Mattos Mda G, Ribeiro RF. Accuracy of stone casts obtained by different impression materials. Braz Oral Res 2008; 22: 293-298.

19) Konstantinos X, Michalakis KX, Stratos A, Hirayama H, Pissiotis AL, Touloumi F. Delayed setting and hygroscopic linear expansion of 3 gypsum products used for cast articulation. J Prosthet Dent 2009; 102: 313-318.

20) Imbery TA, Nehring J, Janus C, Moon PC. Accuracy and dimensional stability of extended-pour and conventional alginate impression materials. J Am Dent Assoc 2010; 141: 32-39.

21) Jemt T, Book K. Prosthesis misfit and marginal bone loss in edentulous implant patients. Int J Oral Maxillofac Implants 1996; 11: 620-625.

22) ISO 5725-1:1994 - Accuracy (trueness and precision) of measurement methods and results, ISO, 2016.

23) Joint Committee for Guides in Metrology, International Vocabulary of Metrology-Basic and General Concepts and Associated Terms 200:2012, 3rd ed., JCGM, 2015.

24) Imburgia M, Logozzo S, Hauschild U, Veronesi G, Mangano C, Mangano FG. Accuracy of four intraoral scanners in oral implantology: a comparative in vitro study. BMC Oral Health 2017;17: 92.

25) Mangano FG, Veronesi G, Hauschild U, Mijiritsky E, Mangano C. Trueness and precision of four intraoral scanners in Oral Implantology: a comparative in vitro study. PLoS One 2016; 11: e0163107.

26) Ajioka H, Kihara H, Odaira C, Kobayashi T, Kondo H. Examination of the position accuracy of implant abutments reproduced by intra-oral optical impression. PLoS One 2016; 11: e0164048.

27) Chew AA, Esguerra RJ, Teoh KH, Wong KM, Ng SD, Tan KB. Three-dimensional accuracy of digital implant impressions: Effects of different scanners and implant level. Int J Oral Maxillofac Implants 2017; 32: 70-80.

28) Mangano FG, Hauschild U, Veronesi G, Imburgia M, Mangano C, Admakin O. Trueness and precision of 5 intraoral scanners in the impressions of single and multiple implants: a comparative in vitro study. BMC Oral Health 2019; 19: 101.

29) Jemt T. Failures and complications in 391 consecutively inserted fixed prostheses supported by Brånemark implants in edentulous jaws: a study of treatment from the time of prosthesis placement to the first annual checkup. Int $\mathrm{J}$ Oral Maxillofac Implants 1991; 6: 270-276.

30) Kim Y, Oh TJ, Misch CE, Wang HL. Occlusal considerations in implant therapy: clinical guidelines with biomechanical rationale. Clin Oral Implants Res 2005; 16: 26-35.

31) Wang J, Z Yu, W Zhu, J Cao. Feature-preserving surface reconstruction from unoriented, noisy point data. Comput Graph Forum 2013; 32: 164-176.

32) Bernardini F, Rushmeier H. The 3D model acquisition pipeline. Comput Graph Forum 2002; 21: 149-172.
33) Rusinkiewicz S, Hall-Holt O, Levoy M. Real-time 3D model acquisition. ACM Trans Graph 2002; 21: 438-446.

34) Nedelcu R, Olsson P, Nyström I, Thor A. Finish line distinctness and accuracy in 7 intraoral scanners versus conventional impression: an in vitro descriptive comparison. BMC Oral Health 2018; 18: 27.

35) Li H, Lyu P, Wang Y, Sun Y. Influence of object translucency on the scanning accuracy of a powder-free intraoral scanner: a laboratory study. J Prosthet Dent 2017; 117: 93-101.

36) González de Villaumbrosia P, Martínez-Rus F, García-Orejas A, Salido MP, Pradíes G. In vitro comparison of the accuracy (trueness and precision) of six extraoral dental scanners with different scanning technologies. J Prosthet Dent 2016; 116: 543-550.

37) Kurz M, Attin T, Mehl A. Influence of material surface on the scanning error of a powder-free 3D measuring system. Clin Oral Investig 2015; 19: 2035-2043.

38) Mizumoto RM, Yilmaz B. Intraoral scan bodies in implant dentistry: A systematic review. J Prosthet Dent 2018; 120: 343-352.

39) Joda T, Brägger U. Patient-centered outcomes comparing digital and conventional implant impression procedures: a randomized crossover trial. Clin Oral Implants Res 2016; 27 : e185-e189.

40) Schepke U, Meijer HJ, Kerdijk W, Cune MS. Digital versus analog complete arch impressions for single-unit premolar implant crowns: operating time and patient preference. J Prosthet Dent 2015; 114: 403-406.

41) Navarro M, Michiardi A, Castaño O, Planell JA. Biomaterials in orthopaedics. J R Soc Interface 2008; 5: 1137-1158.

42) Kurtz SM, Devine JN. PEEK biomaterials in trauma, orthopedic, and spinal implants. Biomaterials 2007; 28: 48454869.

43) Jo JY, Yang DS, Huh JB, Heo JC, Yun MJ, Jeong CM. Influence of abutment materials on the implant-abutment joint stability in internal conical connection type implant systems. J Adv Prosthodont 2014; 6: 491-497.

44) Goracci C, Franchi L, Vichi A, Ferrari M. Accuracy, reliability, and efficiency of intraoral scanners for full-arch impressions: a systematic review of the clinical evidence. Eur J Orthod 2016; 38: 422-428.

45) Joda T, Lenherr P, Dedem P, Kovaltschuk I, Bragger U, Zitzmann NU. Time efficiency, difficulty, and operator's preference comparing digital and conventional implant impressions: a randomized controlled trial. Clin Oral Implants Res 2017; 28: 1318-1323.

46) Patzelt SB, Lamprinos C, Stampf S, Att W. The time efficiency of intraoral scanners: an in vitro comparative study. J Am Dent Assoc 2014; 145: 542-551.

47) Yuzbasioglu E, Kurt H, Turunc R, Bilir H. Comparison of digital and conventional impression techniques: evaluation of patients' perception, treatment comfort, effectiveness and clinical outcomes. BMC Oral Health 2014; 14: 10.

48) Khraishi H, Duane B. Evidence for use of intraoral scanners under clinical conditions for obtaining full-arch digital impressions is insufficient. Evid Based Dent 2017; 18: 24-25.

49) Joda T, Katsoulis J, Brägger U. Clinical fitting and adjustment time for implant-supported crowns comparing digital and conventional workflows. Clin Implant Dent Relat Res 2016; 18: 946-954.

50) Means CR, Flenniken IE. Gagging: a problem in prosthetic dentistry. J Prosthet Dent 1970; 23: 614-620.

51) Burzynski JA, Firestone AR, Beck FM, Fields HW, Deguchi T. Comparison of digital intraoral scanners and alginate impressions: Time and patient satisfaction. Am J Orthod Dentofacial Orthop 2018; 153: 534-541. 